\title{
ONTOLOGÍA Y GNOSEOLOGÍA DEL CAPITALISMO EN ISAAC ÍLICH RUBIN: "ENSAYOS SOBRE LA TEORÍA MARXISTA DEL VALOR"1
}

\author{
Santiago Javier Armesilla Conde ${ }^{2}$ \\ Universidad Complutense de Madrid
}

http://dx.doi.org/10.5209/rev_NOMA.2012.v34.n2.40732

Resumen.- Este breve ensayo trata de mostrar por qué Isaac Ílich Rubin es, todavía hoy, el mejor intérprete, comentador y desarrollador de "El Capital" de Carlos Marx, entendiendo el trabajo de Marx como una ontología y una gnoseología del sistema económico capitalista. Para mostrar esto, analizamos las relaciones existentes entre Marx, Rubin y la teoría de la ciencia del filósofo español Gustavo Bueno. De esta manera, podemos interpretar el trabajo "Ensayos sobre la teoría marxista del valor" también como una ontología y una gnoseología del capitalismo.

Palabras clave.- Rubin, capitalismo, teoría del valor-trabajo, Marx, Economía Política, utilidad marginal, ontología, gnoseología, ciencia, tecnología, técnica, verdad científica, Gustavo Bueno, teoría del cierre categorial, circularismo, socialismo, materialismo filosófico.

\begin{abstract}
This concise essay attempts to show why Isaak Illich Rubin is, until today, the best interpreter, commentator and developer of The Capital of Karl Marx, understanding Marx's work as an ontology and a gnoseology of the capitalist economic system. To do this, we analyze the relations existing between Marx, Rubin and the theory of science of the Spanish Marxist philosopher Gustavo Bueno. In this way, we can interpret the work "Essays on Marxist theory of value" also as an ontology and a gnoseology of capitalism.
\end{abstract}

Keywords.- Rubin, capitalism, theory of labor-value, Marx, Politic Economy, Marginal Utility, ontology, gnoseology, science, technology, technique, scientific truth, Gustavo Bueno, Theory of Categorial Closing, circularism, socialism, Philosophical Materialism.

\section{1.- Introducción: Isaac ílich Rubin en el mundo de habla hispana.}

\section{2.- Ontología y gnoseología del capitalismo en Marx y en Rubin.}

2.a. Qué queremos decir con ontología.

2.a.1. El nacimiento de la Economía Política, su contexto tecnológico y sus categorías.

2.a.2. El papel de la filosofía en relación con la Economía Política.

2.a.3. La ontología del capitalismo en los "Ensayos sobre la teoría marxista del valor" de Rubin.

\footnotetext{
${ }^{1}$ (Nota: este artículo fue presentado el día 15 de diciembre de 2011 en el Instituto de Economía de la Academia de Ciencias Rusas de Moscú, en la mesa redonda internacional sobre el legado teórico de Isaac ílich Rubin y el destino de la Economía Política, en inglés, con el título "Ontology and Gnoseology on Isaac Illich Rubin: Essay on Marxist Theory of Value". Por tanto, lo que se presenta en este documento es una traducción al español del original escrito en inglés).

${ }^{2}$ Licenciado en Ciencias Políticas y de la Administración por la Universidad Complutense de Madrid, España. Doctorando en Economía Aplicada. Personal Docente Investigador, Colaborador honorífico del Departamento de Economía Aplicada V de la Facultad de Ciencias Políticas y Sociología de la Universidad Complutense de Madrid.
} 
2.a.4. Otro aspecto importante de la ontología del capitalismo en Rubin: el fetichismo de la mercancía.

2.b. Qué queremos decir con gnoseología.

2.b.1. La gnoseología comparada con la epistemología.

2.b.2. La gnoseología como análisis de las ciencias y otras disciplinas del conocimiento.

2.b.3. Estatus gnoseológico de la Economía Política: la Teoría del Cierre Categorial.

2.b.4. Materia, forma y verdad en la teoría del valor-trabajo en Marx y en Rubin.

2.b.5. El valor como identidad sintética: el cierre tecnológico de la teoría del valor-trabajo.

\section{3.- Conclusión.}

\section{Bibliografía.}

\section{1.- Introducción: Isaac ílich Rubin en el mundo de habla hispana.}

El ruso Isaac Ílich Rubin (12 de junio de 1886 - 25 de noviembre de 1937) es, para algunos autores, el mejor y, al mismo tiempo, el más desconocido de los economistas marxistas del siglo XX. Su trágica vida (desaparecido durante la Gran Purga soviética de 1937), legando una pequeña pero maravillosa producción académica. Está considerado como uno de los mejores desarrolladores de la teoría del valor-trabajo en sentido marxista de su tiempo. Es autor de cinco libros (además de varios artículos y otros escritos): Historia del pensamiento económico, Economía contemporánea de Occidente, Clásicos de la Economíca Política desde el siglo XVII hasta mediados del siglo XIX, La teoría marxista de la producción y el consumo (no traducido del ruso), y Ensayos sobre la teoría marxista del valor (tercera edición de 1928 publicada por Gosudarstvennoe Izdatel'stvo, Moscú-Leningrado). A día de hoy, dos de ellos han sido traducidos al inglés, Historia del pensamiento económico y Ensayos sobre la teoría marxista del valor.

En el mundo de habla hispana solo han sido traducidos dos libros de Rubin. Ensayos sobre la teoría marxista del valor fue traducido por Néstor Miguez, dirigido por José Aricó, fundador del periódico marxista argentino Pasado y Presente (1963-1965). En septiembre de 1974, Pasado y Presente, ya como editorial, publicó los Ensayos... en Córdoba, Argentina, y fue distribuido por Siglo XXI Editores S.A. en Argentina a finales de la década de 1970 (fue reeditado en México en 1977). Veintisiete años después, en marzo de 2011, el primer volumen de su Historia del pensamiento económico ("Los mercantilistas"), traducido al español por el profesor y economista marxista Diego Guerreron (Maia ediciones, Madrid 2011). Guerrero planea traducir el resto de volúmenes de este libro. Guerrero, además, parte de los análisis de Rubin para desarrollar direcciones nuevas en la teoría económica marxista española. En otros países, como Argentina, Rolando Astarita es uno de los más importantes economistas marxistas que desarrolla algunas ideas que 
Rubin estudió en sus trabajos económicos. Pero el legado rubiniano no es solo importante en Economía Política en el mundo de habla hispana. En Sociología, el español Juan Miguel Valdera de la Universidad de Granada está desarrollando investigaciones interesantes acerca de las relaciones sociales entre clases e instituciones en la Unión Soviética, siguiendo algunas ideas de Rubin (Valdera además habla ruso e inglés).

No hay duda de que en muchos casos, a la hora de estudiar las contribuciones teóricas de una persona, es necesario que aquellos que estudien las teorías de alguien puedan hacerlo en su lengua materna, para una mejor y más sencilla expansión y entendimiento de sus ideas. Pero una cooperación internacional en el campo académico es necesario para lograr esto, y especialmente en el legado de Isaac Rubin, como autor poco conocido fuera de Rusia, e incluso en la Rusia misma. Por ello, la traducción al español de los trabajos de Isaac Rubin, no solo en España sino incluso en otras naciones hispánicas, se requiere necesariamente la cooperación internacional con la Academia rusa y con otras naciones, incluyendo el mundo anglosajón (u otros países europeos como Alemania), donde el conocimiento sobre las teorías de Rubin tiene más tradición.

Por el momento, los trabajos traducidos, especialmente los Ensayos... (el más importante, el más traducido de los trabajos de Isaac Rubin), sirven de sólida base en el mundo hispánico para el análisis, no solo en economía, sino también en los campos sociológico y tecnológico, siguiendo vías muy interesantes que enlazan el legado rubiniano con los desarrollos teóricos de la tradición marxista española. Vías que pueden expandirse si los trabajos de Rubin pudiesen ser traducidos al español, trabajando junto a colegas internacionales en la publicación y expansión del legado de este economista soviético siendo este, sin duda, el mejor tributo que podemos ofrecerle.

\section{2.- Ontología y gnoseología del capitalismo en Marx y en Rubin.}

\section{2.a. Qué queremos decir con ontología.}

\section{2.a.1. El nacimiento de la Economía Política, su contexto tecnológico y sus categorías.}

Para desarrollar una idea coherente de lo que tratamos de exponer, queremos hacer constar que, para poder entender la importancia de lo que atribuimos al trabajo de Rubin, nuestras afirmaciones en torno a esta cuestión seguirán una metodología expositiva de tipo escolástico, esto es: definición de los principales conceptos, desarrollo de la cuestión y una conclusión final.

Tal y como hemos dicho, en este artículo trataremos de mostrar por qué el trabajo de Rubin (y por consiguiente, El Capital de Marx) es una ontología y una gnoseología del sistema económico capitalista. Para hacerlo, debemos definir qué entendemos por ontología y qué por gnoseología. Es necesario un sólido armazón que permita demarcar esta cuestión, porque solo entonces, a nuestro juicio, puede fundamentar la importancia teórica y empírica del 
desarrollo que Rubin realizó de la teoría del valor-trabajo (desde ahora TVT). Sabiendo de antemano que Rubin fue economista, no tratamos de enmarcar su trabajo académico fuera de la Economía Política y situarlo solo dentro de la Filosofía y de la Teoría de la Ciencia. No tratamos de molestar a ningún economista, alentando el intrusionismo entre disciplinas, que a veces es inevitable, pero que en ocasiones supone un desafío intolerable muchas veces con razón. Pero la importancia de los trabajos económicos de Marx, y aquí, sin duda, incluimos también los desarrollos de los mismos que llevó a cabo Isaac ílich Rubin, desborda el campo económico. Un campo continuamente entrecruzado por elementos de otros diversos campos (tecnológico, científico, político y filosófico, también psicológico). Nuestro acercamiento gnoseológico a la Economía Política nos permite ver que ésta no es una "ciencia cerrada", como lo es cualquiera de las Ilamadas Ciencias Naturales o las Ciencias Formales (Matemáticas, Geometría, etc.). Pero, al igual que el resto de las llamadas "Ciencias Humanas" (las Matemáticas y la Física son, hasta donde sabemos, desarrolladas también por seres humanos racionales organizados socialmente), la Economía Política no es una disciplina cerrada, entretejida con, e influida por, otras ciencias naturales y sociales (humanas). Más tarde explicaremos qué entendemos por gnoseología. Por ahora, diremos que es inevitable que la Economía Política sea un campo no cerrado, aunque hay franjas dentro de esta disciplina cuya verdad gnoseológica es mayor que en otras. Y la importancia de Rubin en este aspecto es fundamental.

Además, la Filosofía y la Economía Política (junto con otras disciplinas) sufren constantemente una influencia recíproca. No solo porque algunos de los más importantes economistas de la Historia fueron también filósofos (Adam Smith, Marx, Jevons, etc.). Pero el enfoque ontológico de la realidad que esos filósofos siguieron afectó necesariamente a los desarrollos gnoseológicos de sus teorías económicas. El caso de Marx es claro, debido a la influencia de la dialéctica hegeliana en El Capital. En Jevons, por ejemplo, no puede entenderse su teoría de la utilidad marginal sin la influencia de Bentham. Esto es esencial, pues no decimos que la Filosofía, especialmente la Filosofía de la Ciencia (gnoseología), tenga que inmiscuirse en la Economía Política y viceversa, ni tampoco que ambas sean lo mismo (y esta relación es similar entre la Filosofía y otras disciplinas del conocimiento, sean científicas o no). Lo que estamos diciendo es que las ciencias no proceden de la Filosofía, sino necesariamente de las tecnologías. $Y$ al mismo tiempo, las ciencias permiten el desarrollo de nuevas tecnologías (las revoluciones científico-técnicas). Por ejemplo, la Geometría proviene de las tecnologías propias de agrimensores y albañiles. La Química proviene de las tecnologías desarrolladas en herrerías y tintorerías. Quizás pueda decirse que la Filosofía en nuestra tradición (la tradición helénica), distinta de las tradiciones de tradiciones diferentes (India, China), es moldeada en gran medida por la Geometría porque, de hecho, la Filosofía pretende ser una "geometría de las ideas" (ideas que cruzan categorías y abren caminos a través de ellas). Los "primeros filósofos", como Platón, Anaxágoras, Pitágoras, etc., fueron grandes geómetras, lo que no significa que la Geometría provenga de la Filosofía pero tampoco lo recíproco. Por lo que la Filosofía y las ciencias tienen diferentes fuentes, pero estas fuentes pueden converger (no sin turbulencias), y cuando convergen se modifican mutuamente. 
La Economía Política no es propiamente una ciencia, y no tiene únicamente un origen tecnológico. La Economía Política surge como disciplina en el siglo XVII, al mismo tiempo que la metafísica de Descartes, Malebranche y Leibniz. Mediante un proceso llamado "inversión teológica" esta metafísica gira, en parte, a la Mecánica y, también, a la Economía Política.

En la constitución de varias ciencias particulares, y de las especialidades categoriales conectadas con el lenguaje escrito (Astronomía, Geometría, etc.), fue esencial el proceso de diferenciación de clases de especialistas profesionales, como por ejemplo los artesanos, los ingenieros, los especialistas religiosos y otros. Este proceso de diferenciación se desarrolló al mismo tiempo que el proceso de división de clases sociales. Esto hizo muy complicada la conexión entre estos procesos, pero sin confundirlos entre sí. Estos eventos tuvieron su culminación en la Edad Moderna, al principio de la constitución de varias ciencias y otras disciplinas del conocimiento.

Este origen histórico ha permitido la emergencia y conformación de una pluralidad de ciencias particulares, relativamente autónomas entre sí, que ha permitido establecer relaciones categoriales no solo gramaticalmente. Y la pluralidad efectiva de las ciencias particulares sirve como base para instaurar categorías ontológicas para cada ciencia y para cada disciplina particular, incluida la Economía Política.

En el momento en que una nueva unidad científica es constituida, se produce el proceso que llamamos "cierre categorial". Este es un proceso histórico, institucional, sociológico, antropológico y, en otro sentido, también lógicomaterial y gnoseológico. Explicaremos esto mejor cuando definamos qué entendemos por gnoseología. De momento, afirmaremos que todas las ciencias provienen de oficios manuales diversos. Así pues, las categorías científicas se desarrollan en base a una particular tradición profesional. En el caso de la Economía Política, dejando a un lado a filósofos profesionales (Platón, Aristóteles, Santo Tomás, De Oresme, Hume, Adam Smith, Stuart Mill, Marx, Jevons, etc.) y aparte de pioneros como William Petty o Quesnay, y la institucionalización académica de la Economía Política por parte de Alfred Marshall, si perforamos el velo filosófico de los orígenes de la Economía Política, podemos encontrar en su conformación un origen tecnológico, desarrollado en paralelo, pero no después, a las interpretaciones de las actividades económicas de diversas sociedades que realizaron algunos filósofos. Schumpeter, en su Historia del análisis económico, afirma que la Economía Política no podría conformarse ni desarrollarse aparte de una tradición viva de banqueros, contables, comerciantes, amanuenses, jefes de Estado o estudiosos no profesionales de la materia. Gradualmente, ellos fueron cerrando la Economía Política en un sentido categorial, si no enteramente, al menos en regiones parciales de su propio campo. Estas adherencias, en determinados momentos, actuaron como mecanismos de bloqueo de la Razón económica en sentido categorial. Pero, sin embargo, al mismo tiempo, estas adherencias hicieron posible el corte entre estas y las categorías económicas propiamente dichas. 
Así pues la Razón económica académica, la de los teóricos de la Economía Política, tiene una cercana conexión, por tanto, con lo que podría llamarse Razón económica "mundana", la de aquellos que, por ejemplo, depositan su dinero en un banco, de aquellos que invierten un capital en la bolsa o en una compañía, o de aquellos que operan con medios de producción para producir bienes. Las relaciones entre las Razones económicas académica y mundana son la base del campo de la Economía Política. Y ambas son producto de las relaciones de producción. Es importante aclarar que entendemos por Razón económica la característica de lo que ha sido construido operatoriamente (por procesos de composición y separación). Además, esta característica posee una estructura identificable y reproducible en un contexto biológico o social. Esta Razón (académica y "mundana") existe, como todas las otras razones científicas y tecnológicas, como un desarrollo histórico de las relaciones de producción. Esto no significa que la Economía Política sea la "madre de todas las ciencias". Solo afirmamos que las modernas ciencias categoriales y otras disciplinas son construcciones históricas institucionalizadas y desarrolladas a través del desarrollo de las relaciones de producción en el sistema económico capitalista (y en el socialismo real del Imperio Soviético).

\section{2.a.2. El papel de la filosofía en relación con la Economía Política.}

Las relaciones de producción son, en los Ensayos... de Rubin, la clave del análisis marxista del capitalismo. Para Rubin, el materialismo histórico de Marx (como su sistema filosófico en torno a la Historia, las sociedades políticas, las clases y los sistemas económicos) y su TVT giran alrededor de un mismo problema: las relaciones entre las fuerzas productivas y las relaciones de producción. Por lo que el principal asunto en ambas es el mismo: los cambios en las relaciones de producción dependiendo del desarrollo de las fuerzas productivas. Y si la Economía Política, para Rubin, es esencialmente el estudio de una formación socioeconómica definida (el capitalismo), la crítica de la Economía Política en Marx es, antes que nada, una crítica filosófica de esta disciplina en el momento en que Marx escribió El Capital. Esta crítica, seguida por Rubin en sus Ensayos..., muestra a la economía marxista, según la vía Marx-Rubin, como una reclasificación crítica de las categorías del campo económico. Por lo que si esta reclasificación está relacionada con lo que existe realmente (el sistema económico capitalista), esta reclasificación crítica es absolutamente ontológica porque la ontología es la parte de la filosofía que tiene que ver con lo que está ahí, con lo que es, con lo que existe realmente. Si la ontología es el estudio de la naturaleza del Ser, la Existencia y la Realidad, la ontología del capitalismo de Marx y Rubin no es solo el estudio económico de este sistema económico, sino también el estudio filosófico de la naturaleza del Ser, la Existencia y la Realidad del capitalismo. Esto nos permite ahora definir el papel de la Filosofía en el conjunto del saber, en general, y en relación a la Economía Política en particular.

Para definir este papel, tomaremos la definición de Filosofía del filósofo español Gustavo Bueno, desarrollador del sistema llamado Materialismo Filosófico (la definición está incluida en su ensayo El papel de la Filosofía en el conjunto del saber, Editorial Ciencia Nueva, Madrid 1970). 
Para Bueno, el conocimiento filosófico no es un conocimiento doxográfico, no es un conocimiento en tiempo pasado, sobre las obras de Platón, Aristóteles, Spinoza o Hegel, La Filosofía es un conocimiento sobre el presente y por el presente. La Filosofía, en términos de Gustavo Bueno, es un "saber de segundo grado", que presupone por tanto otros saberes "de primer grado" previos, como los saberes tecnológicos, matemáticos, políticos, biológicos, económicos, etc. La Filosofía, en su sentido estricto, no es "la madre de las ciencias"; la Filosofía presupone un estado de maduración suficiente de la ciencia y la tecnología que pueda comenzar a preparar la Filosofía como una disciplina definida. Por esta razón, la Filosofía trata de ideas que brotan precisamente de la confrontación entre los más diversos conceptos técnicos, políticos, económicos y/o científicos, partiendo de un cierto grado de desarrollo. Estos conceptos son más abundantes a medida que ocurre este desarrollo.

Como "saber de segundo grado", la Filosofía no puede ser asignada a un campo categorial cerrado, como la Física o las Matemáticas. Porque el "campo filosófico" está en función de otros, de sus analogías o de sus contradicciones. Las líneas identificables conformadas por las analogías y contradicciones entre las ciencias y otros contenidos culturales, son llamadas por Gustavo Bueno ideas. Estas, en un sentido científico y tecnológico, nos muestran la Filosofía no más como una actividad orientada a contemplar un mundo diferente desde el mundo real conceptualizado. En nuestro presente, en todas sus partes, es conceptualizado por la técnica y la ciencia, porque no hay realmente "tierras vírgenes" de conceptos. Para dejar ir a las ideas desde los conceptos, la Filosofía no puede concebir ideas que no desciendan de conceptos categoriales o tecnológicos. Pero la Filosofía es necesaria para desligar las ideas de los conceptos, porque los conceptos están "cargados de ideas". De esta manera, rehuimos fórmulas utópicas que proponen definir la Filosofía a través de pomposos conceptos psicológicos, como que "la Filosofía es el amor por el saber", o "la Filosofía es la búsqueda de las causas primeras", o "la Filosofía es el acercamiento a las cuestiones de la existencia". En cambio, nosotros decimos: la Filosofía es la confrontación con las ideas y con las relaciones sistemáticas entre las ideas. Pero sin la necesidad de asumir que las ideas constituyen un mundo organizado y compacto. Las ideas son de muy diferentes rangos, aparecen en diferentes niveles en el tiempo; ni están completamente separadas, ni completamente entrelazadas. La idea de Dios no es una idea eterna, aparece en una fecha más o menos determinada en la Historia. Ideas como progreso y cultura no son ideas eternas: son ideas modernas, con no más de un puñado de años de vida. Su ritmo de transformación suele ser más lento que el ritmo de transformación de las realidades científicas, económicas, políticas o culturales de las que emergen.

Por tanto, la Filosofía, no tiene un contenido que deba ser explotado o descubierto por sí mismo y en sí mismo, ni siquiera ser "creado". La Filosofía existe en función de las realidades de su presente, es una actividad "de segundo grado", y por ello es la búsqueda de una "filosofía auténtica", si ella puede ser encontrada en algún lugar particular. El proceso que Gustavo Bueno llama Filosofía es, por ejemplo, cuando encontramos contradicciones entre una ley física y una ley matemática. Cuando esto ocurre debemos decir: "Yo no busco la Filosofía, pero he de encarar contradicciones entre ideas $y$ 
situaciones. $Y$, desde ahí, lo que busco son los mecanismos bajo los que ha sido producida esa contradicción, sus analogías con otras, etc.".

Así pues, hemos definido qué entendemos por Filosofía, y su papel en el saber en general. En particular, con la Economía Política y otras "ciencias sociales", el papel es el mismo desde un punto de vista ontológico. Debido a ello, Marx y Rubin determinan en sus trabajos que una crítica de la Economía Política, desde las bases del Materialismo Histórico, debe enfrentar las contradicciones entre las ideas de que los economistas tenían sobre la economía y las situaciones reales del sistema económico capitalista. Marx, y Rubin, habían determinado, no solo siguiendo los métodos de la Economía Política, sino también los métodos de la Filosofía (ontología y gnoseología), algunas de las contradicciones entre ideas y situaciones en el sistema económico capitalista, los mecanismos que se han producido bajo sus contradicciones y sus analogías con otros. Por ello, en este sentido, obras como El Capital o los Ensayos... son obras filosóficas, son ontología y gnoseología del capitalismo.

\section{2.a.3. La ontología del capitalismo en los "Ensayos sobre la teoría marxista del valor" de Rubin.}

A pesar de un cierto sustancialismo metafísico, criticado por Kant, la ontología es una parte esencial de la Filosofía. El materialismo filosófico tiene su propia ontología, muy lejos de la metafísica o de hipótesis idealistas. No vamos a dar en este artículo una descripción completa de la ontología materialista. Pero es necesario e interesante para los objetivos de este artículo mostrar lo básico de la misma, ya que la ontología del materialismo filosófico se divide en dos niveles que no deben confundirse: el nivel de llamada "materia ontológicogeneral", que se ocupa del Ser, la realidad tal y como es (incluida la parte de la realidad que no conocemos todavía, y también la parte de la realidad que no conoceremos jamás), y el nivel de la llamada "materia ontológico-especial", que estudia los contenidos dados a escala de las operaciones (praxis), de la conciencia, y que conforma el Mundo que conocemos como una realidad ontológica. El sistema económico capitalista es parte de esa realidad ontológica. Y Rubin, siguiendo a Marx, desarrolla en sus Ensayos... un estudio de este sistema a escala operatoria que ayuda a conformar nuestra vida social y económica. No en vano, para Rubin -y también para Hilferding-, el materialismo histórico y la TVT tienen el mismo punto de partida, esto es, el trabajo como elemento básico de las sociedades humanas (el trabajo es realizado a escala de la conciencia operatoria y ayuda a conformar el Mundo que conocemos como una realidad ontológica). El desarrollo del trabajo institucionalizado y racionalizado en sociedades políticas determina en última instancia el desarrollo de todas estas sociedades.

La actividad laboral de las personas está en constante cambio, a veces más rápido y a veces más lento, y según el momento histórico su carácter será diferente. Para Rubin, estos procesos de cambio y de desarrollo de las actividades laborales implican cambios de dos tipos: en primer lugar, cambios en los medios de producción y en los métodos técnicos con que los hombres actúan sobre la naturaleza, por ejemplo, cambios en las fuerzas productivas de 
las sociedades políticas; en segundo lugar, en relación a estos cambios, se producen otros también en la estructura de las relaciones de producción entre individuos, entre participantes de un proceso social de producción. Las formaciones económicas, o los tipos de sistemas económicos, difieren en la naturaleza de las relaciones de producción entre las personas. La Economía Política teórica investigará una formación socioeconómica definida, en este caso la economía comercial capitalista.

El sistema económico capitalista representa la unión de los procesos técnicomateriales y sus formas sociales, es decir, todas las relaciones de producción entre las personas. Las actividades específicas de los sujetos en el proceso técnico-material de producción presuponen relaciones de producción entre ellos, y viceversa. $Y$ al final $-y$ esta es la base del trabajo de Rubin como una ontología y una gnoseología del capitalismo- la meta definitiva de la Economía Política es entender el capitalismo como una totalidad, como un sistema específico de fuerzas productivas y de relaciones de producción entre personas. Pero para encarar este objetivo, la Economía Política debe distinguir en primer lugar, a través de la abstracción, dos aspectos diferentes del sistema económico capitalista: el aspecto técnico y tecnológico y el aspecto socioeconómico, el proceso técnico-material de producción y su forma histórico-social, las fuerzas productivas materiales y las relaciones sociales de producción. Cada uno de estos dos aspectos del proceso económico es objeto de ciencias distintas. El estudio de la ingeniería social, incluso en estado embrionario, debe convertir en su objeto de análisis las fuerzas productivas de la sociedad en su interacción con las relaciones de producción. Por otra parte, la Economía Política teórica trata las relaciones de producción específicas de la economía capitalista en su interacción con las fuerzas productivas de la sociedad. Cada uno de estas dos características, que solo tratan con un aspecto del proceso productivo en su totalidad, requiere la presencia del otro en la forma de un curso que subyace las investigaciones en Economía Política. Aunque la Economía Política trate sobre las relaciones de producción, siempre presupone su irrompible enlace con el proceso de producción técnico-material, y esto tiene en cuenta un punto y un proceso específico de intercambio de fuerzas productivas materiales.

Para Rubin, es necesario entender que los fenómenos estudiados en El Capital, son propios de un sistema económico específico, si queremos entender este libro. Por eso, para él, el ajuste de las relaciones de producción en las fuerzas productivas -un proceso que toma la forma de las contradicciones crecientes entre las relaciones de producción y las fuerzas productivas, y la forma de convulsiones sociales causadas por estas contradicciones- es la cuestión básica para la teoría del materialismo histórico. Así, el método marxista de análisis puede ser resumido como sigue: a) el análisis de las relaciones de producción en las sociedades capitalistas; b) los procesos de cambios causados por la evolución de las fuerzas productivas; c) la emergencia de contradicciones expresadas normalmente en crisis. Este pensamiento económico es, además, pura ontología del capitalismo.

El aspecto técnico-material del proceso de producción capitalista no es algo muy tratado en la Economía Política, pero sí es su forma social, la totalidad de 
las relaciones de producción que constituyen la estructura económica del capitalismo. Las técnicas y tecnologías productivas (las fuerzas productivas) son incluidas en la teoría económica de Marx solo como curso, como punto de partida tomado en consideración por la amplitud necesaria para la explicación de su genuino objeto de análisis: las relaciones de producción. No obstante, debemos ahora aclarar un aspecto ontológico esencial de la TVT según Rubin. Es verdad que la distinción entre el proceso material y el soporte técnico para la producción y sus formas sociales es esencial en Marx, de acuerdo con Rubin, y esto ayuda a definir la Economía Política como una "ciencia social e histórica". El proceso técnico-material podría ser la base donde se desarrollan las relaciones de producción. Para Rubin es la clave que permite comprender los sistemas económicos y la teoría ontológica de Marx sobre el capitalismo. Gracias a esta base tecnológica, las sociedades políticas produce las relaciones necesarias entre los hombres. Pero la base técnica-tecnológica y sus formas sociales, como base y superestructura respectivamente, no son compartimentos estancos. Se necesitan mutuamente para funcionar, como el árbol necesita las raíces (base) y las hojas (superestructura, que recoge el agua de la lluvia, el aire y la luz del sol), porque sin hojas el árbol muere. De ese modo, el sistema económico capitalista no podría existir sin su base técnica material. Pero esta no sería la misma sin las vías sociales que la permite desarrollar. $Y$ esta idea ontológica es esencial para entender el capitalismo, y también otros sistemas económicos complejos, como formas historicas y sociales temporales, así como las mercancías que el capitalismo permite producir.

Gustavo Bueno entiende, desde las coordenadas del materialismo filosófico, que base y superestructura son conceptos conjugados. Esta idea nos permite entender la ontología de Rubin (y de Marx) de manera más clara. Conceptos conjugados es una expresión usada para referirse a un conjunto de pares de conceptos cuyas oposiciones entre los términos de cada par no se reducen a las clásicas competiciones de contradictoriedad, retroceso y contradicción. Estos conceptos conjugados son esos pares de conceptos cuyos términos (A/B) soportan el dilema del sistema completo de conexión de diagramas, llamadas por Bueno conexiones "metamérica" y "diamérica". Los diagramas de conexión metamérica son conexiones de partes homogéneas de $A(a 1, a 2, \ldots$, an) establecidas a través de $B$, sin ser reducidas a $B$. Lo que permite decir que $B$ ha sido "infiltrada" entre las partes de A.

Los conceptos conjugados se desarrollan en dos niveles: a un nivel fenomenológico-histórico y a un nivel esencial, que constituye una superación de la posición previa que valida los diagramas de conexión. En primer lugar tendríamos los diagramas metaméricos de conexión, mientras que en un segundo lugar serían verificados los diagramas diaméricos de conexión.

Un ejemplo, en ciencias, de un par de conceptos conjugados sería "reposo/movimiento". Hasta Galileo, los diagramas de conexión correspondientes a este par de conceptos han sido interpretados como metaméricos: la reducción del movimiento al reposo del pensamiento eleático, la yuxtaposición aristotélica del ser móvil e inmóvil, etc. Pero desde Galileo a 
Einstein, el diagrama de conexión es diamérico: el reposo es concebido como una relación particular entre cuerpos en movimiento.

En el caso de la relación entre base y superestructura, el marxismo tradicional -y el vulgar- identificaron la economía como la base (producción, distribución y consumo), y todo lo demás (como las leyes, la religión, las ciencias, el lenguaje, el arte, la filosofía, etc., en definitiva, todos los productos finales de las relaciones sociales), serían las superestructuras. Pero, realmente, la base es como los huesos y la superestructura es el resto de tejidos del cuerpo de los vertebrados (o las raíces y las hojas de los árboles, como dijimos antes). Porque los huesos, el esqueleto, sostienen el cuerpo (como la base respecto a la superestructura), pero los huesos no se han formado antes que el resto de los tejidos del cuerpo, sino que se han desarrollado junto al resto de tejidos del cuerpo, desde sus diversas hojas blastomérdicas. Desde aquí pueden estudiarse evolutivamente las funciones de "columnas" que atraviesan la "factoría" del organismo. Esto es como decir que la base económica de una sociedad organizada no podría ser considerada como un estrato previamente desarrollado en que lo "sobrante" podría ser transformado en varias morfologías superestructurales, que podrían caer en recesión tan pronto como la base perdiese su propia consistencia. Pero la concepción de Rubin del capitalismo, y siguiendo el pensamiento de Marx, dentro de un estricto materialismo histórico, ayuda a ver que la base, con su propia morfología, se ha estructurado desde la llamada superestructura que, consecuentemente, deberían también perder su designación (deberíamos llamarlas "estructuras envolventes").

Por ejemplo, es sabido que el petróleo, a lo largo del siglo $\mathrm{XX}$, y más aún todavía, es uno de los componentes básicos de nuestro sistema económico y está en la raíz de muchos conflictos internacionales. Particularmente está implicado en los actuales conflictos entre musulmanes y cristianos, debido a la creencia por parte de muchos de los primeros de que el petróleo fue depositado por Alá en el subsuelo de sus naciones, siendo esta la base de recuperación de tantos pueblos árabes que hasta hace unos pocos decenios eran incluidos entre los pueblos marginados del Mundo o subdesarrollados.

El resurgir de los movimientos islámicos, particularmente de los yijadistas, a lo largo del siglo $\mathrm{XX}$ y hoy día, tuvo como base las columnas de pozos de petróleo. En estas columnas de petróleo, de las que son propietarios algunos países musulmanes, descansa el resurgir de su poder. Sin embargo, es bien sabido (descontando a la teología coránica) que ni el poder político ni el poder económico de los países árabes surgió directamente de la venta de petróleo, pues aunque Alá depositó el crudo entre estos territorios, los países árabes no tenían tecnología para extraerlo, refinarlo e incorporarlo a la red de máquinas y aparatos diseñados para mover motores de explosión de coches, aviones, ferrocarriles, turbinas, etc. Este es solo el segmento de una estructura envolvente, segregada del Todo, adquiriendo la condición de un sujeto de asignación del movimiento global. No se trata, por tanto, de hablar de la base económica como si se tratara de una estructura previa dotada de dinamismo autónomo. Lo que ha venido llamándose base, o infraestructura (en términos del materialismo cultural de Marvin Harris), siempre estuvo rodeada de otras 
estructuras heredadas y más complejas. Ni las artes, ni las ciencias, ni las religiones, ni las lenguas, ni el derecho, son superestructuras. Y esto ya fue parcialmente advertido en el propio curso de desarrollo de la teoría soviética por Isaac ílich Rubin, si vemos sus Ensayos..., y el resto de su producción académica, como una ontología del sistema económico capitalista. Además de una necesaria abstracción que permita distinguir el proceso productivo técnicomaterial de las relaciones sociales en el capitalismo, la ontología de Rubin solo podría ser sólida y coherente si vemos estos dos aspectos como partes de un todo (conceptos conjugados). Incluso la teoría soviética de los problemas de la lingüística (El marxismo y los problemas de la lingüística, de Stalin) o la antropología económica marxista (Godelier), a pesar de todo, prisioneros del dualismo base/superestructura, no tuvieron otra manera de recoger las funciones no superestructurales desempeñadas por el lenguaje, el arte, la religión, que reconsiderando todas ellas como características sociales básicas, de la misma manera que Mandeville en su Fábula de las abejas consideraba virtudes a los defectos.

El concepto de superestructura estuvo contaminado, quizás desde un primer momento, por la idea de superstición, como una posible derivación vinculada a un derroche de energía que podría haber sido aplicada a otros objetivos superiores. Este criterio se mostró absurdo, pues obligaría a reclasificar los principales contenidos básicos de una sociedad como superestructuras culturales (recordando la "sobriedad" de la simplicidad de la Naturaleza).

En este sentido Rubin dice que la Economía Política no es una "ciencia" que trate sobre las relaciones entre las cosas como pensaban los economistas vulgares, ni tampoco sobre las relaciones entre las personas y las cosas, como se afirma desde la teoría de la utilidad marginal, sino que trata sobre las relaciones entre personas en el proceso de producción, que es lo mismo que decir que las relaciones entre personas a través de cosas. Cosas, bienes, producidos gracias a un particular, histórico, sistema económico. Cosas que son al mismo tiempo fuerzas productivas y medios de producción, lo que consolida aún más la relación base/superestructura como conceptos conjugados. Cuando observamos el desarrollo de las categorías económicas debemos siempre tener en mente que el sujeto -la moderna sociedad capitalista en el caso de Rubin- es algo dado en la realidad ( $y$ en la mente, porque sabemos que existe). Las categorías expresan, por tanto, formas de estar, determinaciones de la existencia y, en ocasiones, simples aspectos de este sujeto. Además, en el método teorético de la Economía Política es necesario que el sujeto esté siempre presente tanto en representación como en premisa. Por eso, finalmente, podemos decir que estas relaciones circulares entre personas a través de cosas (a través de bienes que solo pueden producirse en un sistema económico capitalista y solo podrían circular en él) es la idea que determina la conjugación necesaria entre base y superestructura que permite ver la TVT de Marx-Rubin como pura ontología del sistema económico capitalista.

2.a.4. Otro aspecto importante de la ontología del capitalismo en Rubin: el fetichismo de la mercancía. 
Empezando por una asunción sociológica particular, esto es, la estructura social de la economía, la Economía Política da, ante todo, las características de esta forma social de economía y las relaciones de producción que le son específicas. Marx, y también Rubin, dan estas características en su teoría del fetichismo de la mercancía, llamada por Rubin "teoría general de las relaciones de producción en la economía capitalista comercial". Para Rubin, esta teoría es la base de todo el sistema teórico económico marxista, y en particular de su TVT.

El fetichismo de la mercancía es un aspecto muy importante de la ontología del capitalismo en Marx y en Rubin. Marx vio las relaciones humanas subyaciendo a las relaciones entre cosas (las relaciones entre personas a través de cosas), revelando la ilusión en la conciencia humana originada en una economía de mercado, y su conexión con las cosas características que tienen su origen en las relaciones sociales establecidas por los hombres en el proceso productivo. Para Marx, las relaciones de producción y consumo no son relaciones entre cosas. Pensar que son relaciones entre cosas equivale a dar a las cosas características nacidas de las relaciones de producción, y es entonces cuando nace el fetichismo de la mercancía.

Según Rubin, la teoría del fetichismo de la mercancía disipa de la mente de los hombres la ilusión y gran decepción que origina la apariencia del fenómeno en la economía de mercado, y la aceptación de que esta apariencia es la esencia del fenómeno económico. Esta apariencia es el movimiento de las cosas, de los bienes y de sus precios comerciales. Actualmente, esta teoría revela que las relaciones sociales de producción adoptan inevitablemente la forma de cosas y no pueden expresarse más que a través de cosas. La estructura de la economía de mercado hace que las cosas jueguen un papel social particular muy importante, por el que las cosas adoptan propiedades sociales particulares. Marx descubrió, según Rubin, los fundamentos económicos objetivos que dirigen el fetichismo de la mercancía (Rubin también dice que el fetichismo de la mercancía es una "propedéutica" de la economía política).

Estos fundamentos objetivos, materiales, tienen una enorme y esencial importancia para entender los Ensayos... de Rubin y El Capital de Marx como una ontología del capitalismo (también como una gnoseología, a lo que nos referiremos más tarde). Pues en la economía de mercado, todos los organizadores y administradores de la producción a pequeña y gran escala son productores independientes de mercancías. Toda compañía particular es autónoma, su propietario es independiente, cuida de sus intereses y decide sobre el tipo y cantidad de las mercancías que produce. Sobre la base de la propiedad privada tiene a su disposición las herramientas productivas y las materias primas necesarias para producir, siendo además el propietario legal competente del producto de su compañía (los medios de producción, las mercancías antes de su venta, la "plusvalía", etc.). La producción es directamente administrada por productores de mercancías separados en sentido microeconómico. No por la sociedad. La sociedad (política) no regula directamente la actividad laboral de sus miembros, no prescribe lo que debe ocurrir y cómo y cuánto debe ocurrir en este campo. Pero la división social del 
trabajo une a todos los productores de bienes en un sistema unificado que recibe el nombre de "economía nacional", y la Economía Política es Economía Nacional, porque el Estado es la variable y la categoría económica más importante. El Estado administra la producción, la distribución, la propiedad y el consumo, incluso en el más "liberal" de su clase. Lo que Rubin afirma como axioma es que sin el Estado, no hay relaciones entre las personas a través de cosas. Y sin el Estado, el comercio es imposible con otras sociedades políticas, porque la "economía nacional" (el Estado), es un "organismo productivo" cuyas partes están interrelacionadas y condicionadas.

Esta conexión viene del intercambio, con el mercado (y por la interrelación entre mercados, entre economías nacionales), en donde los bienes de cada productor individual aparecen en forma despersonalizada como copias separadas de una clase particular de bienes, independientes de quién las produjo y de dónde se produjeron, y de las condiciones específicas en que se produjeron. Los bienes, los productos de los productores individuales de mercancías, se mueven y son evaluadas en el mercado. Las conexiones y actuales interacciones entre compañías individuales, que podemos llamar autónomas e independientes, surgen de la comparación del valor de los bienes y su intercambio. En el mercado, indirectamente, las sociedades regulan indirectamente la actividad laboral de los hombres, porque el movimiento de mercancías, la subida y bajada de sus precios comerciales, originan cambios en la distribución de la actividad laboral de los productores separados de mercancías, determina la redistribución de las fuerzas productivas de la sociedad y causa su entrada en ciertas ramas de la producción o su salida desde esas ramas.

La interacción y mutua influencia de la actividad laboral de los productores individuales de mercancías se llevan a cabo exclusivamente a través de cosas, a través de los productos de su trabajo que aparecen en el mercado. Rubin muestra cómo los Estados influyen en este asunto con este ejemplo. La expansión de tierras cultivadas en Argentina o Canadá podría causar un decremento en la producción agrícola europea solo si los precios comerciales de los productos agrícolas disminuyen en el mercado. De manera similar, la expansión de la producción a gran escala arruina a los artesanos, haciendo imposible que sigan produciendo lo que antes producían, llevándoles a abandonar el campo para establecerse en las ciudades.

Así que, resumiendo, en líneas generales, los fundamentos objetivo-materiales de la teoría del fetichismo de la mercancía y, por tanto, también de la ontología del capitalismo de Marx y de Rubin son los siguientes:

a) El proceso de producción técnico-material en la base y su forma social como superestructura son conceptos conjugados que determinan cualquier sistema económico racional y complejo, en este caso específico el sistema económico capitalista. Pero podemos distinguir ambos por un proceso de abstracción.

b) Las personas en el campo económico tienen relaciones entre sí a través de cosas, bienes producidos por personas en el mismo campo 
económico a través del trabajo social organizado e institucionalizado, la división social del trabajo.

c) La división social del trabajo se desarrolla en el territorio de una "economía nacional", de un Estado, por células individuales de producción, compañías privadas separadas (relacionadas entre sí por el comercio de bienes en mercados comerciales particulares, por ejemplo, los mercados de medios de producción). La división social del trabajo hace posible que la gente esté materialmente relacionada entre sí en un territorio nacional. Esta "dialéctica de Estados" permite el comercio internacional y amplifica las relaciones sociales entre las personas a través de cosas.

d) La conexión directa entre productores individuales de bienes se realiza para el intercambio, y esto tiene un efecto indirecto en su actividad económica.

\section{2.b. Qué queremos decir con gnoseología.}

\section{2.b.1. La gnoseología comparada con la epistemología.}

Una vez que hemos expuesto la ontología del capitalismo de Isaac ílich Rubin, ahora podemos definir y profundizar en su gnoseología, también siguiendo la teoría económica, y filosófica, de Carlos Marx.

Es importante justificar por qué escogemos gnoseología como término para describir ciertos procesos y eventos en el campo económico por Marx y Rubin en vez de utilizar el término epistemología o "teoría del conocimiento". Desde las coordenadas del materialismo filosófico de Gustavo Bueno, la gnoseología es un término opuesto a epistemología y a "teoría del conocimiento". En ambos su uso no está restringido a la relación sujeto/objeto de la epistemología, una relación puramente psicológica, sino que va relacionada a una tercera parte, la Verdad. Por lo tanto, la gnoseología no se refiere a un conocimiento cierto o falso, sino a una realidad efectiva, construida mediante operaciones, como son concebidas las ciencias y otras disciplinas. Es una teoría (o un tratado) de las ciencias, desde una perspectiva muy particular (perspectiva lógico-material, no psicológica ni epistemológica, ni sociológica, ni lógico-formal ni histórica). Bueno distingue dos tipos de gnoseología: gnoseología general y gnoseología especial.

La gnoseología general se orienta hacia la determinación de una idea general de la ciencia para estimar el grado de cientificidad característica de una disciplina específica. Implica dos aspectos:

1) Gnoseología analítica general, o analítica: diseñada para determinar, "analítica" o estructuralmente, las partes formales constitutivas de todas las ciencias.

2) Gnoseología sintética general, o sintética: estudia la dinámica de la constitución "fisiológica" de la ciencia en operación. 
La gnoseología especial se orienta hacia la determinación de la constitución y de los límites internos de una ciencia positiva específica ("gnoseología de la aritmética", "gnoseología de la mecánica clásica", etc.). No puede cargarse sobre las espaldas de la gnoseología general, ni al contrario.

El materialismo filosófico usa el término epistemología como opuesto al término gnoseología referida a la llamada "teoría del conocimiento verdadero" (sea científico, precientífico o "mundano" -praetercientífico-). Su campo está organizado alrededor de la distinción sujeto/objeto (cognoscente/conocido). El campo de la gnoseología está organizado alrededor de la distinción materia/forma, aplicado a las ciencias.

\section{2.b.2. La gnoseología como análisis de las ciencias y de otras disciplinas del conocimiento.}

En primer lugar, gnoseología significa aquí, por supuesto, el análisis de las disciplinas científicas, como la Geometría, la Termodinámica, etc. Por analogía de atribución, la gnoseología significa el análisis de cualquier otra disciplina como tal (disciplinas técnicas o tecnológicas). Aunque no todas ellas son científicas en el sentido de las ciencias positivas. Su organización para enseñar la obliga a adoptar una estructura similar a la de las ciencias positivas. En la tradición aristotélica de los Segundos Analíticos eran conocidos como ciencias. Por tanto, distinguimos el término gnoseología del término epistemología, reservando el último para todo lo que tenga que ver con el análisis del conocimiento (por ejemplo, en el sentido de la" epistemología genética" de Piaget), haya o no organización como "disciplina".

Una disciplina es inseparable, por supuesto, de la materia en torno a la que se desarrolla. La Musicología es inseparable de la materia constituida por las sinfonías, las sonatas, las óperas, etc. La Etnología es inseparable del campo formado por las sociedades pre-estatales (tribus amazónicas o australianas, por ejemplo). No obstante, las disciplinas son separables de sus respectivas áreas, pero no más que por la posibilidad de compararlas entre sí, en concordancia con términos similares o equivalentes (homólogos o análogos que se producen en el fondo de la sintaxis gnoseológica pragmática en el nivel ontológico). Es precisamente la dualidad entre gnoseología y ontología la que tiene que ver con la disociabilidad de los inseparables -usamos el concepto en un sentido similar al utilizado en Geometría Proyectiva (por ejemplo, la dualidad entre puntos -como la intersección en una recta infinita- y la recta, como una co-alineación de infinitos puntos-)-. No podemos separar el momento gnoseológico del ontológico de una ciencia, pero podemos disociar la perspectiva gnoseológica de la ontológica que le es propia. Cuando hacemos esto, nos encontramos primero con el "cuerpo de la disciplina" en cuestión, y en segundo lugar, nos encontramos con la materia de la disciplina, con la realidad ontológica en sí misma.

En sentido gnoseológico, una disciplina consiste, en efecto, en primer lugar y sobre todo, cualquiera que sea su materia, en un conjunto de instituciones técnicas y/o sociales, como libros, profesorados, departamentos, congresos, asociaciones profesionales de especialistas con sus tradiciones 
correspondientes, etc. Y esto, se trate de la Mariología o la Termodinámica. Existen revistas y congresos internacionales de Mariología, en los que se confrontan escuelas diversas, al igual que en la Termodinámica. El análisis de Hans Kuhn hizo famoso acerca de los paradigmas y las comunidades científicas tiene que ser referida y estimada también a las disciplinas en general, sean científicas o no. No solo hay "paradigmas" y "cambios de paradigma" en Termodinámica, también en Mariología. Por lo que la teoría de los paradigmas de Kuhn es, sobre todo, más una "teoría de las disciplinas" que unicamente una "teoría de las ciencias".

Esto crea una gran confusión que amenaza a quien habla de "comunidades científicas" porque, de acuerdo con lo que hemos dicho, ambas comunidades mariologistas y termodinamicistas- mantienen, desde un punto de vista estructural, social, e histórico, mutuas y extraordinarias similaridades, sin que esas similaridades hagan posible el considerar a la comunidad de los mariologistas como una comunidad científica en sentido específico. Preferimos hablar, por nuestra parte, de "comunidades disciplinares" (incluyendo a las comunidades científicas), y no de "comunidades científicas" incluyendo a las meramente disciplinares. Porque, a pesar de estas comunidades, no es serio que el único criterio para definir un campo exitoso de investigación sea ver si hay un grupo lo suficientemente grande de científicos (comunidades científicas) consideran un campo determinado o no de interés profesional, porque entonces la verdad científica es reemplazada por el consenso.

\section{2.b.3. Estatuto gnoseológico de la Economía Política: la Teoría del Cierre Categorial.}

En nuestra presentación propusimos, para comprender el estatus gnoseológico de la Economía Política en general, y de la gnoseología del capitalismo en Marx y en Rubin en particular, la teoría gnoseológica del materialismo filosófico de Gustavo Bueno como herramienta analítica. Esta teoría gnoseológica, esta teoría de las ciencias en plural, se llama teoría del cierre categorial (TCC). Para no extendernos demasiado, trataremos solo el análisis a través de la TCC de la Economía Política, mostrando también algunas características particulares de esta teoría, que después relacionaremos con los desarrollos gnoseológicos de Isaac Ílich Rubin en sus Ensayos....

Gustavo Bueno publicó en 1972 su propio análisis de la Economía Política, titulao "Ensayo sobre las categorías de la Economía Política" (La Gaya Ciencia, Barcelona 1972). En este trabajo está ya concebida la TCC en una de sus primeras aplicaciones. $Y$ en este trabajo quedó clara la importancia del estudio filosófico de la Economía Política para además delimitar el estatus gnoseológico de esta disciplina, como también para sugerir las implicaciones antropológicas y políticas que se derivan de este ejercicio. Después de cuarenta años, se impone -a nuestro juicio- una recuperación crítica de los conceptos fundamentales de la Economía Política, como bienes de consumo, valor, clases sociales, Estado, etc. Es necesario repensar la Razón económica como un momento inexcusable para una verdadera visión filosófica de los eventos políticos y sociales del presente, sin detrimento del hecho de que esos 
términos pueden desbordar la Economía Política, por lo que se requerirá la intervención de la Filosofía.

Para no estar forzados a negar el lugar ontológico y gnoseológico de la verdad científica existe la TCC. Esta teoría presenta una teoría de la verdad científica como una "identidad sintética". La TCC nos presenta la verdad científica, no como la identidad analítica establecida entre dos términos, expresados en una proposición aislada, sino más bien como un teorema, que ahora no solo realiza múltiples propuestas sintácticas, sino también semánticas y pragmáticas. Las identidades sintéticas aparecen entonces en el curso de operaciones categoriales cerradas. Para describir brevemente la noción de cierre operatorio es suficiente recordar, como hace esta noción en Matemáticas o en Geometría, estando basada en los términos y las relaciones establecidos entre ellos, que podemos conformar nuevos términos en el campo, como cuando en Geometría, de la rotación de un triángulo en un círculo obtenemos un cono, un nuevo término, sin necesitar de cualquier sujeto que participe en el campo.

Ahora expondremos, muy esquemáticamente, el ejercicio de la TCC aplicada a la Economía Política, no como una mera alternativa yuxtapuesta a otras filosofías de las ciencias (ni yuxtapuesta al análisis económico) que trata de subsumir y triturar teorías previas, en un intento de clarificar, aún minimamente, estas cuestiones de orden y distinción de las ciencias. Esto nos permitirá exponer las congruencias entre la TCC y la gnoseología del capitalismo en Marx y en Rubin.

¿Es la Economía Política una ciencia desde la perspectiva de la TCC? Y si la respuesta es sí, ¿qué clase de ciencia es?

Los términos (variables, constantes) del lenguaje económico académico nunca pueden ser sintácticamente autónomos, porque la Economía Política no es una ciencia natural, ni una ciencia formal, sino una ciencia real. Los términos siempre refieren a la realidad económica que es al mismo tiempo un lenguaje, un producto de la razón, que por sí mismo puede ser más o menos categorizado. Términos como trabajador, producción, mercado, mercancía, "desarrollo de las fuerzas productivas", etc., refieren a la vez a las mismas realidades radiales, o a las realidades circulares como "reaciones sociales de producción". Sobre esa base realista, en la que asumimos ya funcionando a la Economía Política, haciendo al tiempo referencias al lenguaje, más o menos, categorizado, debemos determinar si la razón económica cierra, que es tanto como decir en teoría qué es lo específico del campo económico.

¿Qué es entonces lo específico de la Economía Política como ciencia? Cuando los académicos estudian la economía nacional desde el punto de vista de la Economía Política entonces empiezan con la población, la división de esta en clases, su distribución en las ciudades, en el campo y cerca de la costa, las diferentes ramas de la producción, la importación y la exportación, la producción y el consumo anuales, los precios de los bienes, etc. Parece apropiado empezar con lo que es real y concreto, por premisas efectivas. En Economía Política por la población, que es la base y sujeto de todo el proceso social de producción. Pero esto no es, como dijo Marx, lo específico de la 
Economía Política como ciencia. Es en El Capital y en los Ensayos sobre la teoría marxista del valor -entre otras obras- donde Marx y Rubin ofrecen un análisis de lo que consideran el núcleo, el átomo, de la Economía Política. Por supuesto, como dijimos en nuestra definición ontológica, hay personas enlazadas en el campo económico por relaciones circulares, a través de cosas, pero estas relaciones deben darse de un modo específico en la categoría económica. Precisamente, la manera específica de realizar estas relaciones circulares entre personas, entre sujetos económicos, es mediada por, y combinada con, los bienes. Aunque los sujetos del campo económico, como módulos -debido a que su trabajos, independientemente de que estos trabajos sean bienes económicos o no- pueden ser considerados como el origen y medida del valor, es imposible para ellos relacionarse económicamente si no es a través de cosas. Entonces tenemos que ser capaces de introducir el campo económico racional como un concepto dialéctico que incluya una referencia a lo pre-racional, como campo en el que los términos aparecen precisamente definidos por relaciones simétricas, transitivas y reflexivas (relaciones circulares entre personas a través de cosas), tan pronto como son establecidas por la mediación de bienes. Para mantener sus límites económicos, es esencial, para poder comprender la gnoseología del capitalismo que estamos argumentando, considerar los bienes físicos porque son objetívamente segregables de los módulos (de las manos de los trabajadores manuales que producen estos bienes físicos y sus valores).

Cuando en el capitalismo parte del capital variable se dedica a la reproducción del trabajador, y no -por ejemplo- son producidos bienes de consumo para los ciudadanos, el sistema económico está cerrando la recurrencia del trabajo, y al mismo tiempo el trabajo es cosificado (esto implica, en general, la cosificación de las relaciones sociales de producción). En mayor o menor grado, la cosificación es siempre resultado de cierre por razones económicas (que se produce, por ejemplo, al calcular las necesidades nutricionales de una población de trabajadores). Entonces, la especificidad de la economía se basa en ciertas relaciones establecidas entre los hombres y mediadas a través de cosas. Relaciones que son capaces de generar nuevos bienes (términos) para el campo económico.

De acuerdo a la TCC, los cierres operatorios de cada ciencia (y no sus implicaciones a un objeto en particular) son lo que determina la unidad de cada ciencia, su distinción del resto de ciencias y la distinción entre ciencias, pseudociencias, ideologías, religiones, etc. Uno de los requerimientos fundamentales para el cierre es la segregación del sujeto temático e histórico de su campo. Tomando como parámetro la segregación de las operaciones del sujeto temático (sujeto gnoseológico) y sabiendo que las operaciones del investigador están necesariamente presentes en todas las disciplinas, Gustavo Bueno distingue entre metodologías alfa-operatorias y beta-operatorias. En las metodologías alfa-operatorias, el sujeto operatorio desaparece completamente del campo (situaciones alfa-1) como ocurre en las ciencias naturales y formales. El sujeto operatorio desaparece parcialmente en situaciones en que se reconoce al sujeto temático como operatorio. Estas situaciones son las llamadas alfa-2. En las metodologías beta-operatorias también se observan dos momentos o situaciones, pero en ellas el sujeto es parte constitutiva del campo, 
y es imposible segregarlo (tratando de construir las verdades científicas de las ciencias en la misma escala de operaciones, lo cual es imposible). Las ciencias que usan metodologías beta-operatorias se nos aparecen como ciencias anómalas, incapaces de ofrecer verdaderas verdades científicas. Dos estados o situaciones, como dijimos, se pueden distinguir de acuerdo a las relaciones que median entre el sujeto gnoseológico o temático en el campo y el sujeto operatorio (el investigador). La situación beta-1 ocurre cuando el sujeto gnoseológico es capaz de reconstruir las operaciones del sujeto temático (por ejemplo, en Historia). La situación beta-2 nos presenta una continuidad total entre las operaciones de los sujetos, próxima al territorio de las prácticas y de las técnicas.

Entre las llamadas "ciencias humanas" coexisten los dos tipos de metodologías que hemos distinguido (alfa y beta), de tal modo que estas disciplinas tan irregulares deben ser organizadas simultaneamente de acuerdo a estas diferentes metodologías, dependiendo si, más o menos, segregan a los sujetos operatorios de su campo. Así, la Economía Política alcanzará estados alfa-1 en la Termoeconomía; alcanzará estados alfa-2 en la economía clásica, que empezando por las operaciones de los agentes económicos construye algunas estructuras genéricas de carácter matemático, como funciones, curvas, etc.; beta-1 será el Estado que alcance la Praxeología; y beta-2 el de la Política Económica. Es decir, la segregación progresiva del sujeto gnoseológico, de proximidad cercana al estado alfa-operatorio y viceversa. Aquí toma en su sentido completo la idea de cosificación del sujeto (módulo) en el campo económico. Porque la teoría del fetichismo de la mercancía también tiene que ver con la cosificación de las relaciones sociales, incluyendo la cosificación de los propios sujetos, incluyendo su fuerza de trabajo. Esta es otra cuestión esencial de la gnoseología materialista del capitalismo, porque la cosificación es un "resultado del cierre", que nos lleva a pensar que el máximo cierre (los estados alfa) se da cuanto mayor sea la cosificación. Los agentes económicos (los módulos) tendrían que comportarse no como humanos, con capacidad de "libre albedrío", porque lo específicamente humano ha sido la "parte" segregada del sujeto, pero los productores y los consumidores están forzados por la espiral del contexto.

No podemos concluir este punto sin tratar sobre los estados intermedios en alfa y beta, importantes para continuar con el siguiente asunto: los estados I y II alfa y beta-operatorios.

Sabiendo que las metodologías beta-1 son características de las disciplinas científicas que han de regresar de las operaciones a las estructuras o esencias determinantes sin desbordar el territorio operatorio, pero sentando en cierto sentido qué puede formarse en la misma área, podemos distinguir una vía genérica, y otra específica, de estas metodologías. En el modo genérico (Ibeta1) las determinaciones serán establecidas a través de objetos o artefactos técnicos o tecnológicos, a su vez producidos por operaciones (la coincidencia entre la verdad y el hecho). En el modo específico (II-beta1), la determinación de operaciones podría ser constituída por otras operaciones, como podría ser el caso de la Teoría de Juegos, 0 de las disciplinas psicológicas del condicionamiento operante. 
Y sabiendo que en el estado alfa-1, después del comienzo de las operaciones que han permitido construcciones anteriores, tienen éxito en el establecimiento de enlaces entre términos del campo como si ellos fuesen ofrecidos independientemente de todo enlace operatorio (que es lo que ocurre en las ciencias naturales y formales), las metodologías alfa-2 no emanan desde conexiones anteriores a cualquier operación, sino de las operaciones mismas, pero progresando de determinados contextos envolventes de estas mismas operaciones, capaces no de establecer enlaces operatorios, estructuras o procesos entre los términos del campo. Los enlaces, estructuras o determinados procesos, o son genéricos a los campos naturales y sociales, y en este caso hablamos de metodologías I-alfa2, o son específicos de campos sociales, y en este caso hablamos de metodologías II-alfa2. Y en este punto debemos repetir que es esencial retomar a Rubin y su desarrollo de la TVT de Marx.

2.b.4. Materia, forma y verdad en la Teoría del Valor-Trabajo en Marx y en Rubin.

Hemos dicho antes que la gnoseología se opone a la epistemología en lo que tiene que ver con la relación entre materia y forma en el momento de establecer la verdad científica. ¿Cómo es la relación gnoseológica entre la materia, la forma y la verdad (científica) en la TVT de acuerdo con Rubin y siguiendo a Marx?

Trataremos de responder a esta cuestión de manera esquemática. De esta manera, sentaremos las bases gnoseológicas de la TVT (la producción material técnica y tecnológica de bienes y valores y precios asociados a ellos), sin ahondar en otros desarrollos complejos de las teorías económicas de Rubin, que desbordan las pretensiones de este artículo. Resumiremos la gnoseología del sistema económico capitalista de acuerdo a la TVT de Marx-Rubin.

Si la ontología del capitalismo de Marx y Rubin permite ver el proceso social de producción como un todo (las relaciones sociales de producción), la gnoseología del capitalismo debe permitirnos abstraer necesariamente y "separar" las formas sociales que las relaciones humanas adoptan en el capitalismo, incluyendo su proceso de producción técnico-material, y este proceso en sí mismo. $Y$ es en este proceso de producción técnico-material donde se da la relación gnoseológica materia-forma-verdad. Donde el bombeo de sangre del sistema económico capitalista es desarrollado. Porque el bombeo de sangre del capitalismo es la producción de bienes, como Marx deja claro al comienzo del Tomo I de El Capital. Los bienes son la forma social, histórica, tecnológica concreta que adopta la materia sobre la que se realizan las operaciones objetivas, y los valores asociados a los bienes (el valor de uso, objetivo e histórico, y el valor), son la verdad gnoseológica derivada de las relaciones entre materia y forma. Esta es la base gnoseológica de la TVT. Veamos cómo lo explica Rubin. 
Hay una conexión y una cerrada correspondencia entre el proceso de producción de bienes materiales y la forma social en que se lleva a cabo, por ejemplo, el conjunto de las relaciones de producción entre los hombres, que está regulada por una condición particular de las fuerzas productivas, esto es, el proceso material de producción. El sistema dado de las relaciones de producción, en cierto sentido, es una entidad cerrada, encabezada por una iniciativa y adaptada al proceso material de producción como un todo. Obviamente, cambios en el proceso material de producción pueden causar cambios inevitables en las relaciones de producción. Pero estos cambios están hechos dentro de esas relaciones y son llevados a cabo por sus propias fuerzas internas, por decisión de sus agencias administrativas. Los cambios son causados por cambios en el proceso de producción. La unidad que existe al comienzo permite una correspondencia entre el proceso técnico-material de producción y las relaciones de producción que lo hacen posible. Después, cada uno de estos elementos se desarrolla sobre la base de un plan dado previamente (podemos decir que el cierre es equivalente a la planificación y la planificación al cierre). Cada elemento tiene su propia lógica interna pero, debido a la unidad inicial, no proporciona ninguna contradicción entre ellos.

Las relaciones de producción no existen de antemano, pero son establecidas a través de la transferencia de cosas de un sujeto a otro. Por esta razón su carácter es material (social). Los objetos se transfieren de un sujeto a otro no por relaciones de antemano, sino por la compra y venta, el comercio, limitado a la transferencia de estos objetos. La transferencia de cosas tiene un significado técnico (y social). Las cosas son bienes en el campo económico.

En una sociedad de mercado, desde el punto de vista del proceso técnico de producción, cada producto del trabajo debe proceder desde un punto de producción a otro, desde una unidad de producción a otra, hasta recibir su forma final y pase desde la unidad de producción del productor final o el comerciante intermedio a la unidad económica del consumidor. Pero dada la autonomía y la independencia de las unidades económicas separadas, la transferencia del producto de una unidad económica individual a otra es posible solo a través de la compra y venta del acuerdo entre dos unidades económicas, lo que significa que se establece entre ellos una relación de producción particular: de compra y venta. La relación de producción entre ciertas personas es establecida en el momento de transferencia, y después de la transferencia es interrumpida otra vez. En el proceso de intercambio fue ligado inextricablemente con las relaciones entre personas y el movimiento de los bienes en el proceso de producción (lo tecnológico y lo social, la base y la superestructura).

La personificación de las cosas (otra característica del fetichismo de la mercancía) permite a sus titulares aparecer y participar en una determinada forma de relación -relación de clase- en relaciones específicas de producción con otras personas. Marx consideró la producción social como un proceso continuo dialéctico recurrente de reproducción en el que cada enlace es el resultado de un enlace previo y la causa del siguiente (rotación recurrente es la idea que, para Gustavo Bueno, está asociada definitivamente con la Razón económica, desde las coordenadas de la TCC). La forma social de las cosas 
(los bienes) es al mismo tiempo el resultado del proceso de producción previo y de expectativas sobre el futuro.

Cuando los participantes en el acto de intercambio han comparado los productos de su trabajo con un tercer producto, este papel lo asume el dinero de manera embrionaria, porque no es dinero antes o después del acto de intercambio. El dinero es una institución clave en cualquier sistema económico complejo. Sin dinero, no hay ninguna traducción física de valor objetivamente mensurable. Y el valor, como la verdad de la gnoseología del capitalismo, es inseparable del dinero de muchas maneras. Y el valor (como el dinero), asociado a los bienes, es también una cosa. $Y$ el proceso para producir esta cosa también tiene una forma social, histórica y tecnológica concreta.

La cosa -el bien y el valor (los precios)- a través del cual las personas caen en definir las relaciones con los demás, juega el papel de "intermediario" o "portador" de la relación de salida dada. Además, siendo técnica o materialmente un bien de consumo concreto o un medio de producción, el bien parece adquirir una existencia funcional o social, por ejemplo, un carácter social particular a través del cual expresa las relaciones de producción dadas, dando a las cosas particulares una forma social particular. De hecho, el valor es solo en si mismo una expresión material de una relación entre las actividades productivas de los hombres. El valor, como una relación social de producción, es representado en un bien, y un bien "representa" una relación de producción. Las relaciones de producción son formas sociales de manipulación de la materia en el campo económico, y los valores son su verdad gnoseológica, pero todos ellos, al mismo tiempo, son relaciones de producción. Las categorías económicas no son más que expresiones teoréticas, "abstracciones" de relaciones de producción (oferta y demanda son relaciones de una determinada producción, como intercambios individuales). La forma de los bienes refleja las propiedades del área social (del campo económico, en un sentido histórico y tecnológico).

La existencia material de los bienes no se opone a su existencia social, porque el segundo presupone el primero, y ambos son igualmente materiales. La existencia social, como existencia material de todas las cosas producidas, está garantizada por la circulación de la misma, a través del valor capitalizado en dinero, el valor del coste de producción, el precio de producción, el precio comercial y todos los intermediarios entre coste de producción y precio comercial, y el valor de uso, institucionalizado y categorizado tecnológicamente a través de instituciones como la Organización Mundial de Aduanas (desarrolladores del Sistema Armonizado de Descripción y Codificación de Mercancías, un procedimiento técnico para la clasificación objetiva de valores de uso en un nivel universal).

La existencia material de los bienes, por otra parte, se debe a las funciones técnicas de esta existencia, porque el aspecto tecnológico se aplica también a la esfera económica, incluso desde "afuera" de la misma (por influencia), y por tanto la actividad laboral está condicionada por ambas, que se combinan sin apenas distinguirlas. 
En este análisis final, Marx nota que hay un proceso de producción técnicomaterial, y lo que hace es tomar un interés en la forma económica y en la forma de determinación histórico-social que adopta el proceso de producción técnicomaterial. Es decir, Marx siguió un método de cierre categorial: materia-formaverdad. Él vio una materia dada, se preguntó por la forma que tomaba esa materia (forma social, histórica, tecnológica e incluso política), y determinó (o trató de determinar) una verdad, producto de una forma social que adquiere la materia. Incluso el valor (la verdad gnoseológica) afecta a las relaciones sociales de producción, entre productores autónomos de bienes, con sus fluctuaciones de valor dependientes de cambios en el proceso técnico-material de producción y su influencia en la distribución de valor en la sociedades políticas (incluso cuando el Estado impone impuestos a las compañías de negocios, empresas y otras instituciones burguesas, tomando una parte esencial del valor producido).

Así pues el punto de partida de la TVT es un medio social específico, una sociedad política con una cierta estructura productiva. En una economía capitalista de mercado, las relaciones laborales de producción entre los hombres, procura necesariamente la forma del valor de las cosas, y solo puede aparecer en forma material; el trabajo en el campo económico), puede ser expresado solo en términos de valor. Aquí el punto de partida de la investigación es el trabajo, como operaciones de los sujetos. El valor es:

a) Una relación social entre personas.

b) Asume forma material (bienes, dinero, precios, etc.).

c) Tiene que ver con el proceso de producción.

El precio de mercado no es proporcional al valor de la mercancía. La cantidad necesaria de trabajo para la producción de un bien es proporcional al llamado "precio de producción" (o precio del productor), que es igual al coste de producción más la ganancia media sobre el capital invertido. El valor representa el nivel medio sobre el que fluctúan los precios comerciales y con los que los precios podrían coincidir si el trabajo social es distribuido proporcionalmente entre varias ramas de producción. El valor de los bienes es directamente proporcional a la cantidad de trabajo necesario para su producción. El intercambio de dos bienes diferentes de acuerdo a sus valores corresponde al estado de equilibrio entre dos ramas diferentes de producción. El trabajo que crea valor no solo aparece como trabajo cuantitativamente distribuido sino también como trabajo socialmente coincidente (o igual), esto es, como trabajo "social", entendido como la masa total de trabajo igual y uniforme de la sociedad. El trabajo tiene estas características sociales no solo en una economía de mercado, sino incluso en una economía socialista, y esto es esencial para comprender la verdad gnoseológica de la TVT.

La cantidad de trabajo socialmente necesario para la producción de una unidad de un producto, que determina el valor, depende a su vez de la productividad del trabajo. La fuerza motriz que transforma el sistema entero del valor se origina en el proceso de producción técnico-material. El valor juega el papel de regulador, y la TVT es la "ley de balance" de la Economía Política. La TVT analiza las leyes del intercambio, las leyes de ecualización de bienes en el 
mercado, solo si esas leyes tienen que ver con las leyes de producción y distribución del trabajo en una economía de mercado. El valor, como producto del trabajo, permite un alineamiento de bienes, la ecualización de diversas formas concretas de trabajo como un componente del trabajo social "total", distribuido en diferentes ramas.

En conclusión, El valor es una relación de producción entre personas que toma la forma de una propiedad de los bienes. Una forma histórica concreta, como cualquier otra mercancía, que solo puede existir en un determinado contexto determinante, que se origina a partir de operaciones institucionalizadas de sujetos sobre la materia de la Naturaleza y/u otras regiones del campo económico, estableciendo relaciones como la que hace surgir el valor final que da expresión a, y también regula, como el bombeo de sangre desde el corazón que circula por todo el cuerpo, el conjunto del proceso social de producción.

\section{2.b.5. El valor como identidad sintética: el cierre tecnológico de la TVT.}

Para finalizar el cierre de la gnoseología del capialismo en Marx-Rubin, y desde las coordenadas de la TCC, nos falta referirnos al valor como identidad sintética. Ahora explicaremos esquemáticamente qué es una identidad sintética. No es este el lugar para hablar de la idea de identidad de manera extendida, porque ello iría más allá de las pretensiones de este breve ensayo. Solo nos referiremos a la idea de identidad en su sentido gnoseológico, y en relación con la TVT.

Para definir el concepto de verdad en relación a la identidad sintética (una vez que hemos relacionado la definición de verdad con la de identidad), puede parecer redundante decir que toda identidad es sintética. Sin embargo, no es así, porque incluso cuando la idea de verdad envuelve a la idea de identidad sintética, no pueden ser mutuamente mantenidas: no puede decirse que toda identidad sintética constituya una verdad gnoseológica. Esto es porque hay varios tipos de identidades sintéticas; ahora solo nos vamos a referir a los tipos más generales que podemos llamar identidades sintéticas: identidades sintéticas esquemáticas (o esquemas de identidad) e identidades sintéticas sistemáticas. Las identidades sintéticas esquemáticas también pueden ser llamadas "configuraciones" o identidades configuracionales, y son realmente el resultado de operaciones. Las identidades sistemáticas son relaciones, y también podrían llamarse "identidades proposicionales", en respuesta a su manera ordinaria de expresión. La verdad científica se asocia con las identidades sistemáticas, y no con las identidades esquemáticas (aunque no por esta razón deban ser consideradas independientes de ellas). En ambos casos, las identidades sintéticas esquemáticas y sistemáticas, hay envueltas operaciones que ocupan un lugar entre varios términos compuestos "sintéticamente".

El proceso constructivo alcanza su estatus científico cuando determina una proposición que expresa una relación de identidad sintética. No obstante, no se puede decir que toda identidad sintética constituya una verdad científica, porque hay varios tipos de identidades sintéticas. La idea de identidad sintética 
está tomada de las Matemáticas. La operación $7+5=12$ muestra un cierre categorial en Matemáticas, siendo 12 una identidad sintética sistemática, porque es trascendental a los términos 7 y 5 mediante la operación + . y la relación $=$. El entrelazamiento de esquemas de identidad da lugar a un contexto determinante, prioritario para la formación de identidades sintéticas. En nuestro ejemplo matemático, el campo cerrado determinante es el campo de los números naturales en Matemáticas, y el cierre ocurre porque 12 es un número natural relacionado con otros números naturales, 7 y 5, por una operación de suma.

En el caso del valor encontramos un esquema de identidad (una identidad sintética esquemática), porque el valor es producto de operaciones en el campo económico técnico-material y productivo (en el campo económico). Por ello no podemos tener una verdad científica en el estado gnoseológico alfa-1. Pero debido a que el valor es un producto cultural producido por trabajadores en el campo económico, que es "segregado" de sus operaciones solo cuando han terminado de producirlo -y ello les permite continuar con la producción de valor(es)- que es también producto de las operaciones de juntar/separar valores (bienes) que también van conformando el bien final hasta completar el coste de producción, y porque ello tiene una enorme influencia sobre la voluntad de aquellos que lo han producido, además de la influencia social que antes hemos referido, el grado de verdad gnoseológica es considerable, mayor que el de la Teoría de la Utilidad Marginal, que no tiene un origen operatorio. Mientras que la utilidad marginal es, aparte de su construcción matemática (idiográfica), una idea extraeconómica (la de utilidad), el valor es un concepto económico-tecnológico. Entonces hay un cierre tecnológico de identidad sintética esquemática que alcanza un grado gnoseológico II-alfa2 (la utilidad marginal, como concesión, no podría nunca rebasar el estado beta-operatorio). Grado que, incidentalmente, alcanza toda la Economía Política clásica, incluyendo a Marx y, por supuesto, a Rubin.

\section{3.- Conclusión.}

En este breve ensayo hemos querido mostrar cómo el legado de Rubin desborda los límites del campo de la Economía Política en la que él se movía, en la misma manera en que Marx desborda ese mismo campo. Hemos mostrado cómo Rubin, a nuestro juicio, es el mejor intérprete de la TVT marxista, quedando sus Ensayos... a la altura de El Capital, como un trabajo esencial y clarificador sobre la realidad capitalista.

Para nosotros, que utilizamos la obra de Isaac ílich Rubin como material de nuestra investigación doctoral (ahora en proceso de escritura), Ensayos sobre la teoría marxista del valor es, como dijimos al principio, en primer lugar y sobre todo, una ontología y una gnoseología del capitalismo, como los trabajos económicos de Carlos Marx. Y decimos esto para tributar a Rubin, además, el mejor homenaje que podemos ofrecerle. 


\section{Bibliografía:}

ARMESILLA, Santiago:

- (2010)“Valor, trabajo, demanda y Estado: esbozo de una teoría circularista-sintética del valor-trabajo", Revista El Catoblepas, n 98, abril, p. 16.

- (2010) "Análisis comparativo de la teoría del valor-trabajo y de la teoría de la utilidad marginal desde la teoría del cierre categoríal", trabajo de investigación para alcanzar la Suficiencia Investigadora y el Diploma de Estudios Avanzados (DEA) del programa de doctorado Economía Política y Social en el Marco de la Globalización, no publicado, Madrid.

BUENO, Gustavo:

- (1970) "El papel de la Filosofía en el conjunto del Saber", Editorial Ciencia Nueva, Madrid.

- (1972) "Ensayo sobre las categorías de la Economía Política”, La Gaya Ciencia, Barcelona.

- (1972) "Ensayos Materialistas", Taurus, Madrid.

- "Teoría del Cierre Categorial", Tomos 1-5, Pentalfa, Oviedo 1992-1993.

DELGADO, Javier:

- (2002) "Sobre la necesidad del estudio filosófico de la Economía Política", Revista El Catoblepas, n² 2, abril 2002, p. 2.

- (2003) "La Economía como disciplina científica", Revista El Catoblepas, $\mathrm{n}^{0}$ 13, marzo, p. 13.

GARCÍA, Pelayo:

- (2002) "Diccionario Filosófico", Biblioteca Filosofía en Español, Oviedo.

MARX, Carlos:

- (2001) "El Capital", FCE, Ciudad de México.

- (2010) "Elementos fundamentales para una crítica de la Economía Política", Siglo XXI Editores, Buenos Aires.

RUBIN, Isaac:

- (1974) "Ensayos sobre la teoría marxista en español", Cuadernos de Pasado y Presente, Buenos Aires.

- (2011) "Historia del Pensamiento Económico. Tomo 1, los mercantilistas", Maia Ediciones, Madrid.

SCHUMPETER, Joseph.:

- (1994) "Historia del Análisis Económico", Ariel Ediciones, Madrid. 


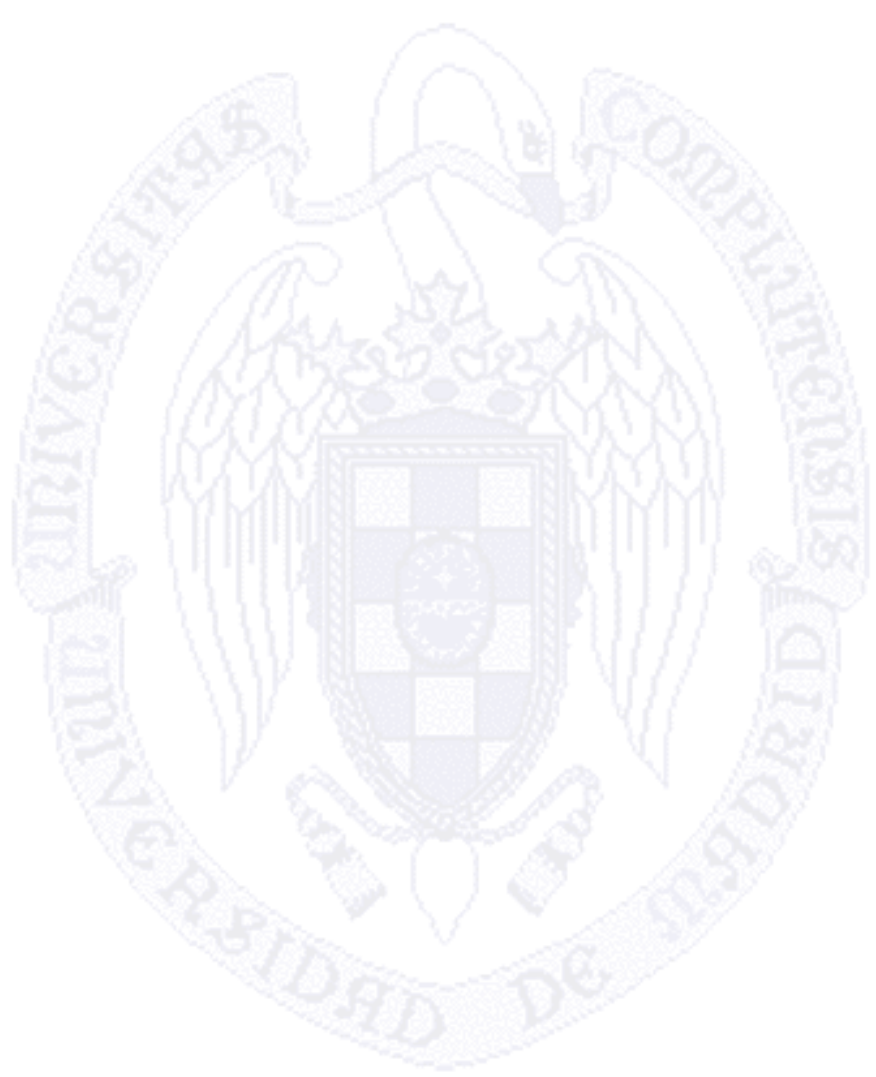

